\title{
Nanometer sized particles for viscosity controlled binders for silk screen printing
}

\author{
A. Kalleder, M. Mennig, H. Schmidt \\ Institut für Neue Materialien, Universität des Saarlandes, Im Stadtwald, D-66123 Saarbrïcken, Germany
}

\begin{abstract}
A water based synthesis route to $\mathrm{PbO}-\mathrm{SiO}_{2}-\mathrm{B}_{2} \mathrm{O}_{3}-\mathrm{ZnO}$ gels and glasses has been developed. In the present study the gel was used for the substitution of organic silk screen printing media and additives in a silk screen printing paste for the decoration of glass with a black enamel. Interparticle forces of the gel particles can control the viscosity of a paste, containing $30 \mathrm{wt} \%$ of the wet gel and $70 \mathrm{wt} \%$ of a commercially available black enamel powder. Beside the rheology controlling function, a consequence of polycondensation of the gel during drying of the printed pastes is, that the sol-gel material acts as a binder. The composition of the gel ensured that during firing the sol-gel material is densified to a glass with properties suitable for the firing process at temperatures between $560^{\circ} \mathrm{C}$ and $640^{\circ} \mathrm{C}$. Because of the particular inorganic gel which was used, no residual organic groups have to be removed during firing.
\end{abstract}

\section{Introduction}

Silk screen printing is a frequently used technique for the decoration of glass. The printing pastes consist of a glass frit, a pigment, organic solvents and organic additives like cellulose compounds. These additives control the rheology of the paste during printing and are used to install thixotropic behavior $[1,2]$. Furthermore organic binders like acrylates are necessary for the fixation of the printed paste [3] after drying to allow handling under industrial conditions.

During the firing process, the organics are burnt and converted into water and carbon dioxide. This conversion requires oxygen under specific conditions, for example, if the printing paste has to be

\footnotetext{
${ }^{*}$ Corresponding author. Tel.: $+49-6813025013$; fax: $+49-681$ 3025223 .
}

placed between two glass panes, for example, as it has to be employed in the pairwise bending process of wind screens. When enamel decorations are used to cover the electric contacts for a heating system, oxygen does not have an easy access. This problem results in an incomplete burn-out with cracking products spoiling the screens. Therefore, an additional step has to be employed in this case, consisting of a separate thermal treatment at $400^{\circ} \mathrm{C}$. Investigations have shown that the addition of oxidizing agents like $\mathrm{Pb}_{3} \mathrm{O}_{4}$ [4] may decrease the problem, but requires an additional component. Other investigations show that the organic binders can be substituted by aluminum phosphates [5]. Problems have been reported, however, from insufficient durability and adhesion.

Low melting inorganic binding systems, however, would represent an interesting solution, if all requirements (adhesion, stability, low melting properties and pigment stabilization) could be fulfilled. One of the systems with low melting properties are lead- 
containing systems prepared by the sol-gel process. There are several publications investigating such systems [6-11], but all these investigations have been based on alcohol as solvent. For practical use, water-based systems are necessary. A water-based four-component system $\left(\mathrm{PbO}-\mathrm{SiO}_{2}-\mathrm{B}_{2} \mathrm{O}_{3}-\mathrm{ZnO}\right)$ has been investigated by Mennig et al. [12] and it was shown that it is possible to prepare xerogels, which can be transformed into glasses between 550 and $640^{\circ} \mathrm{C}$, which is a suitable temperature range for firing of enamels during the float glass bending process.

The objective of the present investigations was to prepare black enamels by using the four-component sol or wet gel as a printing media for commercially available black enamel powders and to employ it by silk screen printing techniques.

\section{Experimental}

Sols were synthesized from lead nitrate, tetraethoxysilane (TEOS), trimethylborate (TMB) and zinc acetate dihydrate in aqueous solution. The detailed sol-gel-synthesis is described elsewhere [12].

$3.0 \mathrm{~g}$ of a wet gel of the composition $83.2 \mathrm{PbO}-$ $12.8 \mathrm{~B}_{2} \mathrm{O}_{3}-2.4 \mathrm{SiO}_{2}-1.6 \mathrm{ZnO}$ were mixed with $7.0 \mathrm{~g}$ of a commercially available black enamel powder (Cooksen Mattey) consisting of $\mathrm{CuCr}_{2} \mathrm{O}_{4}$ and a low melting glass frit to obtain an appropriate paste. Optionally small amounts $(0.3 \mathrm{wt} \%)$ of cellulose compounds were added to obtain thixotropic rheology. For investigating the viscosity in dependence upon the shear rate a rotation viscosimeter (Physica UM) with a cone-plate measuring system was used. After screen printing (polyester screen $68 \mathrm{~T}$ ) decorations were dried for $5 \mathrm{~min}$ at $180^{\circ} \mathrm{C}$ and fired in a preheated muffle furnace at $560^{\circ} \mathrm{C}$ for $12 \mathrm{~min}$. Differential thermal analysis (DTA) and thermal gravimetric measurements (TG) were carried out in $\mathrm{Al}_{2} \mathrm{O}_{3}$ crucibles versus $\mathrm{Al}_{2} \mathrm{O}_{3}$ in synthetic air.

\section{Results}

In this study a sol-gel material with a composition of $83.2 \mathrm{PbO}-12.8 \mathrm{~B}_{2} \mathrm{O}_{3}-2.4 \mathrm{SiO}_{2}-1.6 \mathrm{ZnO}$ was chosen, since its transition temperature of $313^{\circ} \mathrm{C}$ and the viscosity as a function of temperature offer a suitable low viscosity in the temperature range between $560^{\circ} \mathrm{C}$ and $640^{\circ} \mathrm{C}$.

First tests using a sol-gel material with this composition as 'screen printing oil' were on the rheology controlling behavior of the corresponding wet gel. They were carried out using $30 \mathrm{wt} \%$ of the as prepared wet gel with a solid content of $12 \%$ in water and $70 \mathrm{wt} \%$ of a conventional enamel powder based on $\mathrm{CuCr}_{2} \mathrm{O}_{4}$ as a pigment and a low melting glass frit for firing at $560^{\circ} \mathrm{C}$. The rheology of such a paste was determined and was compared to a commercially available printing paste, prepared from the same enamel powder by mixing with silk screen printing oil in a ratio of 3:7, as shown in Fig. 1 in part A.

Fig. 1 shows the viscosities of both pastes for increasing and decreasing shear rates. It is evident that the rheological behavior of the silk screen printing paste, prepared with the wet gel instead of the silk screen printing oil could be adapted to that of a commercially available silk screen printing paste, as one can see from Fig. 1. Thixotropic behavior was obtained by the addition of 0.3 wt\% of MHPC 20.000 to the wet gel. This small quantity of organic additive could be removed during drying avoiding residual volatile compounds. Fig. 2 shows the result of the DTA/TG measurement of this sol-gel paste during thermal treatment.

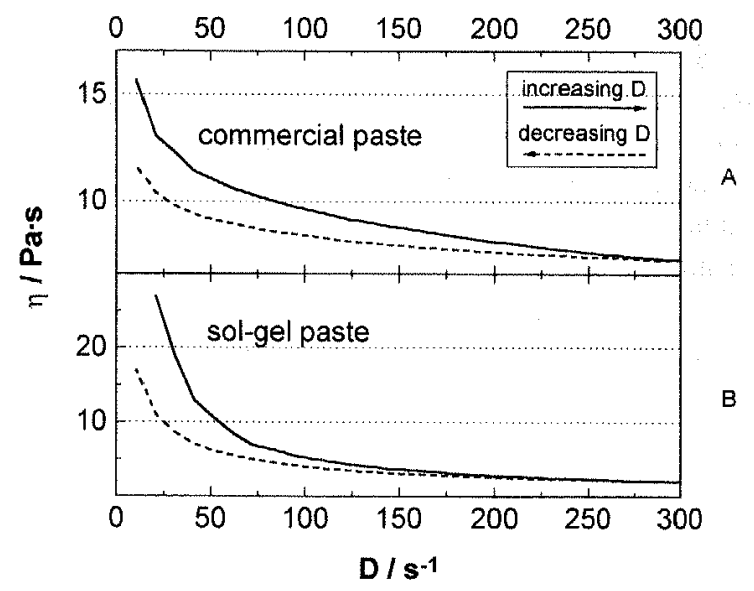

Fig. 1. $\eta(\mathrm{D})$-curve of a screen printing paste for black decorations on glass consisting of $\mathrm{CuCr}_{2} \mathrm{O}_{4}$ as a pigment, a low melting glass frit and a conventional screen printing medium (A) respectively a wet gel (B) of the composition $83.2 \mathrm{PbO}-12.8 \mathrm{~B}_{2} \mathrm{O}_{3}-2.4 \mathrm{SiO}_{2}-$ $1.6 \mathrm{ZnO}$ in $0.3 \mathrm{wt} \% \mathrm{MHPC}$. 


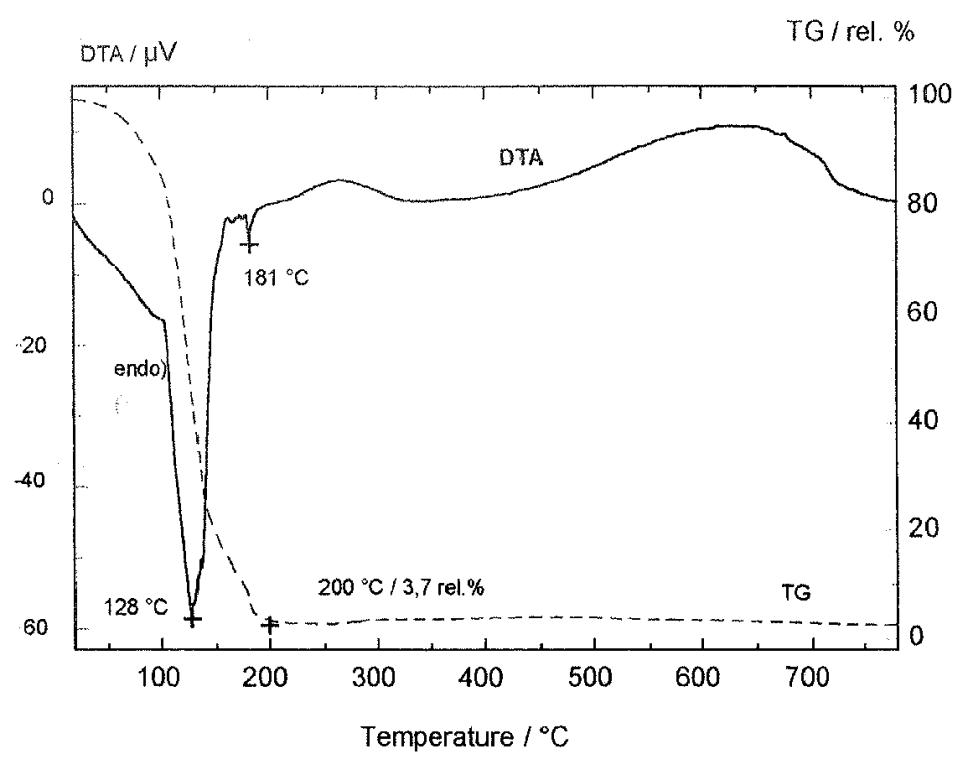

Fig. 2. DTA/TG (DTA straight line, TG dashed line) of the developed sol-gel derived silk screen printing medium based on a gel of the composition $83.2 \mathrm{PbO}-12.8 \mathrm{~B}_{2} \mathrm{O}_{3}-2.4 \mathrm{SiO}_{2}-1.6 \mathrm{ZnO}$ containing $0.3 \mathrm{wt} \%$ of cellulose compounds for installing thixotropic rheology.

The measurement indicates, that the sol-gel derived printing medium does not contain any volatile compounds at temperatures higher than $180^{\circ} \mathrm{C}$. Besides the possibility for removing residual organics

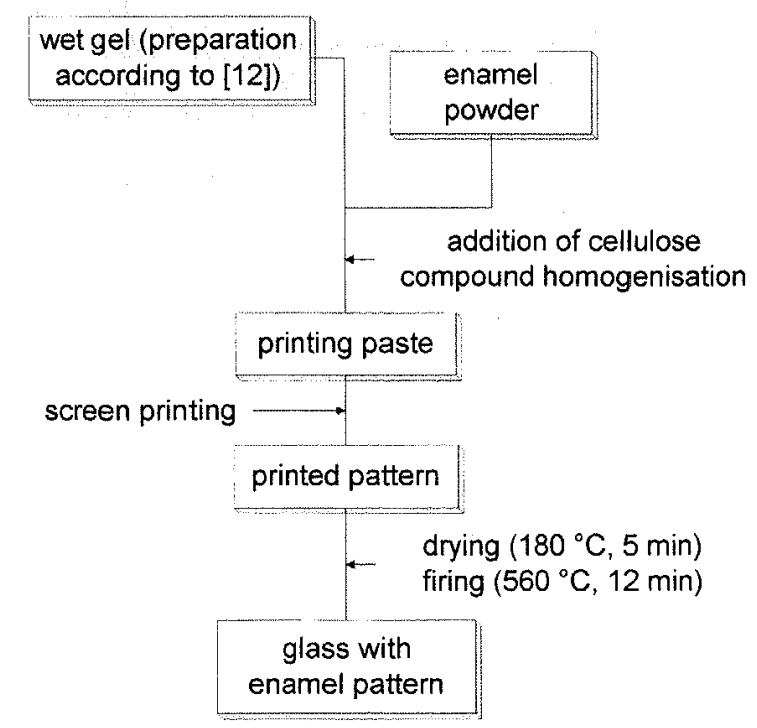

Fig. 3. Scheme of the fabrication of enamelled glass by screen printing techniques using a paste consisting out of a wet gel of the composition $83.2 \mathrm{PbO}-12.8 \quad \mathrm{~B}_{2} \mathrm{O}_{3}-2.4 \mathrm{SiO}_{2}-1.6 \mathrm{ZnO}$ prepared according to Ref. [12] and a commercially available black enamel powder. during drying at $180^{\circ} \mathrm{C}$ it was found that after drying the printed pattern the fixation to the glass substrate could be measured by a pencil scratching test (Erichson test $2 \mathrm{H}$ ). The scheme of the enameling of glass using the developed printing paste is shown in Fig. 3.

Black enameled decorations were obtained on soda-lime glass after firing at $560^{\circ} \mathrm{C}$ for $12 \mathrm{~min}$. Their optical properties were equal to those, obtained with commercially available printing pastes, based on silk screen printing oil.

\section{Discussion}

The thixotropic behavior needed for silk screen printing pastes $[2,3]$ can be seen in Fig. 1 in part A for the commercially available, oil containing paste. The as prepared wet gel showed a constant viscosity of about $200 \mathrm{mPa} s$ over the whole $\mathrm{D}$ range. By adding the enamel powder in the above mentioned ratio structural viscosity was obtained. The viscosity decreases with increasing shear rate in a manner, comparable to that of the oil containing paste. This decrease seems plausible, since the viscosity of oil and wet gel are similar and the powder to liquid ratio of both pastes was the same. Nevertheless the sol-gel paste showed no thixotropic behavior necessary for 
silk screen printing. To install this rheology $0.3 \mathrm{wt} \%$ of MHPC 20.000 was chosen as an additive, because it was expected that only these amounts of this organic additive would provide the required theology. The viscosity as a function of shear rate of such a paste is shown in Fig. 1 in part B.

Beside the fact that this cellulose compound was needed in an amount of only 0.3 wt $\%$ it was furthermore assumed that it could be removed during drying thus avoiding retention of residual volatile compounds. Therefore the behavior of this sol-gel paste during thermal treatment was determined by DTA/TG shown in Fig. 2.

It can be seen that the use of the gel instead of an organic printing medium, produces a printing medium which does not contain volatile compounds at temperatures higher than $180^{\circ} \mathrm{C}$. The endothermic peak at $128^{\circ} \mathrm{C}$ represents the evaporation of water used as a solvent. At $181^{\circ} \mathrm{C}$ the cellulose compound, which was added in an amount of $0,3 \mathrm{wt} \%$, decomposes. Above this temperature no further weight loss was be detected.

The proper adhesion and cohesion is obtained after drying at $180^{\circ} \mathrm{C}$ by interactions of the $\mathrm{OH}$ groups of the hydrolysed silicon and boron alkoxides with the oxide surface of the glass substrate and the enamel powder particles. After drying at $180^{\circ} \mathrm{C}$ decorations were fired without any further thermal treatment immediately in a preheated muffle furnace at $560^{\circ} \mathrm{C}$ for $12 \mathrm{~min}$ resulting in black enameled glass [13] with a thickness of the enamel of about $20 \mu \mathrm{m}$, having an optical quality equal to those of decorations based on commercially available screen printing media.

\section{Conclusion}

An inorganic sol-gel-derived screen printing medium for the decoration of glass has been devel- oped. It can be used instead of commercially available organic additives without changing any processing parameter for decoration of float glass. Because of its composition the gel or xerogel in the $\mathrm{PbO}$ $\mathrm{SiO}_{2}-\mathrm{B}_{2} \mathrm{O}_{3}-\mathrm{ZnO}$ system used as a printing medium is adhered to the glass substrate during firing of the decoration. In addition the to controlling the rheology during printing and as a binder after drying the sol-gel material can substitute a part of the glass frit. Also there is no need to remove residual organics in a separate temperature treatment.

\section{References}

[1] P. Kahanek, Siebdruck mit Keramikfarben auf Flachglas, Vol. 66, Glastechnische Tagung (Kurzreferate), Fulda, 1992.

[2] H. Haug, Dickschichttechnik, Vol. 5, Intemationales Kolloquium Verbindungstechnik in der Elektrotechnik, Fellbach, 1990.

[3] D.E. Riemer, PhD thesis, Technische Universitat Berlin (1988).

[4] A. Andrejewski, M. Honke, K. Masch, R. Albrecht, ER-Pat DE $4132652 \mathrm{Al}$.

[5] A. Andrejewski, M. Honke, K. Masch, GER-Pat. DE 3724 $013 \mathrm{C} 2$.

[6] S.P. Mukherjee, J. Non-Cryst. Solids 82 (1986) 293 .

[7] I. Strawbridge, PhD thesis, University of Sheffield (1984).

[8] I. Strawbridge, P.F. James, Novel Ceram. Fabr. Process, 38 (1986) 251.

[9] M. Yamane, H. Kawazoe, A. Yasumori, J. Non-Cryst. Solids 99 (1988) 160.

[10] H. Dislich, P. Hinz, R. Kaufmann, BRD Pat. DE 1941191.

[11] W. Granier, K. Jabobker, A. Pradel, M. Pham Ti, J. NonCryst. Solids 147\&148 (1992) 574.

[12] M. Mennig, A. Kalleder, H. Schmidt, 'Preparation and characterisation of thermomechanical properties of sol-gel derived glasses in the $\mathrm{PbO}-\mathrm{SiO}_{2}-\mathrm{B}_{2} \mathrm{O}_{3}-\mathrm{ZnO}$ system', 3rd Conf. of European Society of Glass Science and Technology, Wirzburg, Giermany, 1995.

[13] W. Schaefer, W. Goerenz, H. Schmidt, M. Mennig, A. Kalleder, Ger.-Pat. DE $19525658 \mathrm{Cl}$. 